\title{
X-Ray Scattering of Soft Matter
}

\author{
Norbert Stribeck
}

With 92 Figures and 6 Tables

Springer 
Norbert Stribeck

E-mail: norbert@stribeck.de

Universität Hamburg

Institut für Technische und

Makromolekulare Chemie

Bundesstr. 45

20146 Hamburg

Germany 


\section{Preface}

Mehr Licht!

(J. W. v. Goethe)

The application of X-ray scattering for the study of soft matter has a long tradition. By shining X-rays on a piece of material, representative structure information is collected in a scattering pattern. Moreover, during the last three decades X-ray scattering has gained new attractivity, for it developed from a static to a dynamic method.

The progress achieved is closely linked to the development of both powerful detectors and brilliant X-ray sources (synchrotron radiation, rotating anode). Such point-focus equipment has replaced older slit-focus equipment (Kratky camera, Rigaku-Denki camera) in many laboratories, and the next step of instrumental progress is already discernible. With the "X-ray free electron laser" (XFEL) it will become possible to study very fast processes like the structure relaxation of elastomers after the removal of mechanical load.

Today, structure evolution can be tracked in-situ with a cycle time of less than a second. Moreover, if a polymer part is scanned by the X-ray beam of a microbeam setup, the variation of structure and orientation can be documented with a spatial resolution of $1 \mu \mathrm{m}$. For the application of X-rays no special sample preparation is required, and as the beam may travel through air for at least several centimeters, manufacturing or ageing machinery can be integrated in the beamline with ease.

On the other hand, the result of the scattering method is not a common image of the structure. There is not even a way to reconstruct it from scattering data, except for the cases in which either anomalous scattering is employed, or a diffraction diagram of an almost perfect lattice structure is recorded. Because most of the man-made polymer materials suffer from polydispersity and heterogeneity, the crystallographic algorithms of structure inversion are in general restricted to the field of biopolymers (e.g., protein crystallography). Thus the ordinary polymer scientist will deal with scattering data rather than with diffraction data. These data must be interpreted or analyzed. This book is intended both to guide the beginner in this field, and to present a collection of strategies for the analysis of scattering data gathered with modern equipment. Common misunderstandings are discussed. Instead, advanced strategies are advertised.

An advantage of a laboratory-oriented textbook is the fact that many technical aspects of our trade can be communicated ${ }^{1}$. Their consideration may help to improve the quality and to assure the completeness of the recorded data. On the other

\footnotetext{
${ }^{1}$ An example is the chapter entitled "It's Beamtime, Phil". It is written in the hope that in particular the practical work of students will benefit from it.
} 
hand, the concept is restricting the presentation of the mathematical background to a terse treatment. For a field like the scattering that is virtually interpenetrated by mathematical concepts this is not unproblematic. As a consequence, it was impossible to present mathematical deductions, which could have been an assistance to methodical development by the reader. In this respect even the references given to original papers are not really helpful, because in such publications the fundamental mathematical tools are expected to be known. Nevertheless, this restriction may be advantageous from a different perspective. The terse scheme is enhancing the presentation of the fundamental ideas and their repetitive use in different subareas of the scattering technique.

This book with its special focus on application was stimulated by a suggestion of Prof. Dr.-Ing. W.-M. Kulicke. I greatly appreciate his support. Moreover, the manuscript has its roots in thirty years of practical work in the field of scattering from soft materials conducted in several labs and at several synchrotron sources. During this time the author has assisted many external groups with their practical work at the soft-matter beamlines of the Hamburg Synchrotron Radiation Laboratory (HASYLAB at DESY), supported evaluation of scattering data, and worked as a referee in the soft-condensed matter review-committee of the European Synchrotron Radiation Facility (ESRF) in Grenoble. The accumulated handouts prepared during twenty years of lecturing scattering methods at the University of Hamburg have been a valuable source for the book manuscript.

There are many other people who have - in different respect - contributed to this work. The first to mention is my teacher, Prof. Dr. W. Ruland. I am grateful for his art of teaching the scattering. Wherever in this book I should have been able to explain something clearly and concisely, it is his merit. The second to mention is Prof. Dr. H. G. Zachmann. In his group I enjoyed to become involved in many practical issues of soft matter physics. In particular I appreciate many helpful comments on the manuscript that have been supplied by Prof. Dr. W. Ruland, Dr. C. Burger, Prof. Dr. A. Thünemann and Prof. Dr. S. Murthy. In addition, there are many other colleagues who have stimulated my work by fruitful cooperation, discussion and support. To mention them all would fill pages.

The complex task of writing a scientific manuscript has been significantly eased by authoring tools that keep track of the formal aspects of the growing manuscript. For this reason I thank the developers of $\mathrm{LY}_{\mathrm{Y}} \mathrm{X}$, Koma-Script and $\mathrm{LTT}_{\mathrm{E}} \mathrm{X}$ (in particular Matthias Ettrich and Markus Kohm) for their free and superb software. Moreover, I highly appreciate the excellent guidance and the distinguished manuscript editing by the team at Springer Publishers.

Last but not least I express cordial thanks to my wife Marie-Luise and to my children for their continuous support. 


\section{Table of Contents}

1 Polydispersity and Heterogeneity 1

1.1 Scattering, Polydispersity and Materials Properties . . . . . . . . . 1

1.2 Distribution Functions and Physical Parameters . . . . . . . . . . 2

1.2.1 The Number Molecular Mass Distribution . . . . . . . . . . . 2

1.2.2 The Number Average Molecular Mass . . . . . . . . . . . 3

1.3 Moments ..................... 4

2 General Background $\quad 7$

2.1 The Subareas of X-Ray Scattering . . . . . . . . . . . . . . 7

2.2 X-Rays and Matter . . . . . . . . . . . . . . . . . 8

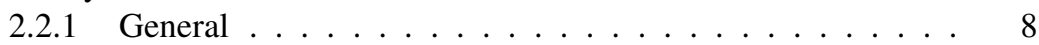

2.2.2 Polarization ...................... 8

2.2.2.1 Polarization Factor of a Laboratory Source . . . . 9

2.2.2.2 Synchrotron Beam Polarization Factor . . . . . . 9

2.2.3 Compton Scattering . . . . . . . . . . . . . . . 10

2.2 .4 Fluorescence .................. . . . . . . . . . . . . 10

2.3 Classical X-Ray Setup . . . . . . . . . . . . . . . . 11

2.4 s-Space and q-Space . . . . . . . . . . . . . . . . . . . . . 11

2.5 Scattering Intensity and Sample Structure . . . . . . . . . . . . . . . . . 13

2.5.1 Lay-Out of the Magic Square . . . . . . . . . . . . . . 14

2.5.2 Analysis Options - Example for SAXS Data . . . . . . . . 14

2.5.3 Parameters, Functions and Operations in the Magic Square . 15

2.5.4 Convolution, Correlation and Autocorrelation . . . . . . . . 16

2.6 Polydispersity and Scattering Intensity . . . . . . . . . . . . . 18

2.7 A Glance at the Mathematical Laboratory of Scattering . . . . . . . 21

2.7 .1 The Slice . . . . . . . . . . . . . . . . 22

2.7.2 The Projection .................... 23

2.7.3 Fourier Slice Theorem . . . . . . . . . . . . . . 23

2.7.4 Fourier Derivative Theorem ............ 23

2.7.5 Breadth Theorem . . . . . . . . . . . . . . . . . 24

2.7.6 Dilation and Reciprocity ...................... 24

2.7.7 DIRAC's $\delta$-Function . . . . . . . . . . . . . . . . . 25

2.7.8 Convolution Theorem .............. 25

2.7.9 Bandlimited Functions . . . . . . . . . . . . . 25

2.8 How to Collect Complete Scattering Patterns . . . . . . . . . . . 26 
2.8 .1 Isotropic Scattering . . . . . . . . . . . . . . . . 26

2.8.2 Anisotropic Scattering . . . . . . . . . . . . . . . 26

2.8.2.1 Single Crystal Anisotropy . . . . . . . . . . . . 26

2.8.2.2 Fiber Symmetry . . . . . . . . . . . . . . 27

2.9 Application of Digital Image Processing (DI) . . . . . . . . . . . 29

2.9.1 DI and the Analysis of Scattering Patterns . . . . . . . . . 29

2.9.2 A Scattering Pattern Is a Matrix of Numbers, Not a Photo . 30

2.9 .3 How to Utilize DI . . . . . . . . . . . . . . . . 30

2.9.4 Concepts of DI that Ease the Analysis of Scattering Images . 30

2.9.4.1 The Paradigm: Arithmetics with Matrices _. . . 30

2.9.4.2 Submatrix Ranking Operators . . . . . . . . . . 31

2.9.4.3 Primitive Operators: Erode, Median, and Dilate . 31

2.9.4.4 Combined Operators: Opening \& Closing . . . . 32

\section{Typical Problems for Analysis by X-Ray Scattering 33}

3.1 Everyday Industrial Problems . . . . . . . . . . . . . . . . . 33

3.2 At the Front of Innovation . . . . . . . . . . . . . . . . . . 34

3.2 .1 Web Resources . . . . . . . . . . . . . . . . . . 34

3.2 .2 Fields of Innovation . . . . . . . . . . . . . . . . 34

3.2.2.1 Visualize and Model Structure Automatically . . 34

3.2.2.2 Study Gradient Materials . . . . . . . . . . . 35

3.2.2.3 Study Thin Films . . . . . . . . . . . . . . 35

3.2.2.4 Study Structure Evolution . . . . . . . . . . . . . 35

4 Experimental Overview 37

4.1 The Shape of the Primary Beam . . . . . . . . . . . . . 38

4.1 .1 Point Focus Collimation . . . . . . . . . . . . . . 38

4.1.2 Slit Focus Collimation . . . . . . . . . . . . . . . . . 39

4.1.2.1 Common Cameras and Properties . . . . . . . . 39

4.1.2.2 Infinite Slit Length . . . . . . . . . . . . . . . 39

4.1.2.3 A Fiber in a Slit-Focus Camera . . . . . . . . . . 40

4.1 .3 Desmearing of Slit-Focus Data . . . . . . . . . . . . . 40

4.1.4 Smearing of Point-Focus Data . . . . . . . . . . . . . 41

4.2 Setup of Point-Collimation Apparatus . . . . . . . . . . . . . 41

4.2.1 The Radiation Source . . . . . . . . . . . . . . . . . . . . . 42

4.2.1.1 Rotating Anode . . . . . . . . . . . . . . 42

4.2.1.2 Synchrotron Radiation . . . . . . . . . . . . . . . 42

4.2.1.3 XFEL: The X-Ray Free Electron Laser . . . . . . 44

4.2.2 Beam Amplification by Insertion Devices . . . . . . . . . . 46

4.2.3 Beam Shaping by Optical Devices . . . . . . . . . . . . 46

4.2.3.1 The Göbel Mirror . . . . . . . . . . . . . . . 46

4.2.3.2 Conventional Synchrotron Beamline Optics . . . 47

4.2.3.3 Microbeam Optics (Wave-Guides, X-Ray Lenses) 47

4.2.3.4 Nanobeam Optics (Kirkpatrick-Baez Mirrors) . . 48

4.2.3.5 Beam-Position Monitoring . . . . . . . . . . 50 
4.2.3.6 Shutters ................ 50

4.2.3.7 Slits ...................... 50

4.2.3.8 Stabilizers ......................... 51

4.2.3.9 Absorbers ............... 51

4.2.4 The Sample Recipient . . . . . . . . . . . . . . . 51

4.2.4.1 Optical Bench vs. Dance Floor . . . . . . . . 52

4.2.4.2 Chambers for Sample Positioning . . . . . . . . 52

4.2.4.3 Recipients for Sample Processing . . . . . . . . 53

4.2 .5 Detectors ................... 53

4.2.5.1 Criteria for Detector Performance . . . . . . . 53

4.2.5.2 CCD Detectors . . . . . . . . . . . . . 54

4.2.5.3 Image Plates . . . . . . . . . . . . . . 55

4.2.5.4 Gas-Filled Detectors . . . . . . . . . . . . 56

4.2.5.5 Other X-Ray Detectors . . . . . . . . . . . 57

4.2.5.6 Detector Operation Mode: Binning . . . . . . . 58

4.2.6 Experiment Monitors . . . . . . . . . . . . . . 58

4.2.6.1 Monitoring, Journaling, Control . . . . . . . . . 58

4.2.6.2 Beam Intensity Monitoring . . . . . . . . . . . 59

4.3 Data Acquisition, Experiment Control and Its Principles . . . . . . 59

4.3.1 Voltage-to-Frequency Conversion (VFC) . . . . . . . . . 59

4.3.2 Unix and the Communication Among Acquisition Modules 61

5 Acquisition of Synchrotron Beamtime 63

5.1 Test Measurements . . . . . . . . . . . . . . . . . . 63

5.2 Support or Collaboration . . . . . . . . . . . . . . . 63

5.3 A Guide to Proposal Writing . . . . . . . . . . . . . . . . 64

6 It's Beamtime, Phil: A Guide to Collect a Complete Set of Data 67

6.1 Be Organized . . . . . . . . . . . . . . . 67

6.2 Very Important: Data File Check . . . . . . . . . . . . . . . . . . . . 67

6.3 Never Store Test Snapshots from Detector Memory . . . . . . . . . 68

6.4 To Be Collected Before the First Experiment . . . . . . . . . . . . . 68

6.4.1 Measurement of the Sample-Detector Distance . . . . . . . 69

6.4.2 Measurement of the Detector Response . . . . . . . . . . 69

6.4.3 Measurement of the Primary Beam Profile . . . . . . . . . 69

6.5 To Be Collected for Each New Run . . . . . . . . . . . . . . . . . . 69

6.6 Adjustments with Each Experiment . . . . . . . . . . . . . 70

6.7 Collect Good Data . . . . . . . . . . . . . . . . . . 70

6.8 To Be Collected with Each Scattering Pattern . . . . . . . . . . . . 71

7 Pre-evaluation of Scattering Data 73

7.1 Reading the Scattering Data Files . . . . . . . . . . . . . . . . . 74

7.2 Assessment of SAXS Multiple Scattering . . . . . . . . . . . . 74

7.3 Normalization . . . . . . . . . . . . . . . . . . . 75

7.4 Valid Area Masking . . . . . . . . . . . . . . . 75 


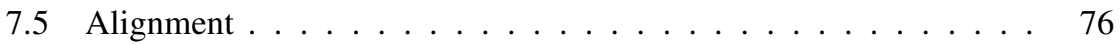

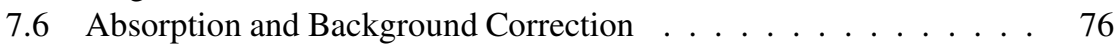

7.6.1 Absorption - the Principle . . . . . . . . . . . . . . . 77

7.6.2 Absorption in Normal-Transmission Geometry . . . . . . . 77

7.6.3 Absorption in Reflection Geometries . . . . . . . . . . . 80

7.6.3.1 Thin Samples in Symmetrical-Reflection Geometry 81

7.6.3.2 Thin Samples in Asymmetrical-Reflection Geometry . . . . . . . . . . . . 82

7.6.4 Calculations: Absorption Factor, Optimum Sample Thickness 83

7.6.5 Refraction Correction . . . . . . . . . . . . . . . . . . . . 84

7.7 Reconstruction of Proper Constitution _ . . . . . . . . . 85

7.8 Conversion to Reciprocal Space Units . . . . . . . . . . . . 85

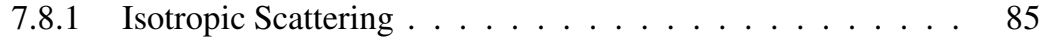

7.8.2 Anisotropic Scattering . . . . . . . . . . . . . . . 85

7.8.2.1 USAXS and SAXS . . . . . . . . . . . 85

7.8.2.2 MAXS and WAXS with Fiber Symmetry . . . . . 85

7.8.2.3 MAXS and WAXS Without Fiber Symmetry . . . 85

7.9 Harmony . . . . . . . . . . . . . . . . . . . . 86

7.10 Calibration to Absolute Scattering Intensity _ . . . . . . . . 86

7.10.1 The Units of Absolute Scattering Intensity . . . . . . . . . 86

7.10 .2 Absolute Intensity in SAXS . . . . . . . . . . . 87

7.10.2.1 The Idea of Direct Calibration . . . . . . . . . . . 87

7.10.2.2 Direct Calibration for the Kratky Camera . . . . . 88

7.10.2.3 Direct Calibration for a Synchrotron Beamline . . 90

7.10.2.4 Indirect Calibration Using a Polymer Sample . . . 91

7.10.2.5 Indirect Calibration by Fluid Standards . . . . . . 92

7.10.3 A Link to Absolute Intensity in WAXS . . . . . . . . . 92

8 Interpretation of Scattering Patterns 95

8.1 Shape of the Scattering Intensity at Very Small Angles . . . . . . 95

8.1 .1 GUINIER's approximation . . . . . . . . . . . . . 95

8.1 .2 Usability for Data Extrapolation . . . . . . . . . . . . . 96

8.1.3 Usability for Structure Parameter Determination . . . . . . 96

8.1.4 Determination of the Parameters of GUINIER's law . . . . . 96

8.1.5 Meaning of the Parameters of GuINIER's Law . . . . . . . 97

8.2 Peak Spotting: WAXS Reflections, Long Periods . . . . . . . . . 99

8.2.1 Discrete and Diffuse Scattering . . . . . . . . . . . . . 99

8.2.2 Peaks in Isotropic and Anisotropic Scattering Patterns _. . 99

8.2.2.1 Isotropy and Anisotropy . . . . . . . . . . . . . 99

8.2.2.2 Where to Search for Peaks of Fibers . . . . . . . 100

8.2.3 WAXS Peaks and Peak Positions . . . . . . . . . . . . . . 100

8.2.4 Determination of WAXS Crystallinity . . . . . . . . . . 102

8.2.4.1 Phenomenon . . . . . . . . . . . . . . . 102

8.2.4.2 Crystallinity Index . . . . . . . . . . . . . . 103

8.2.4.3 WAXS Crystallinity for Undistorted Crystals . . . 103 
8.2.4.4 WAXS Crystallinity Considering Distortions . . . 104

8.2.5 WAXS Line Profile Analysis . . . . . . . . . . . . . . . . 104

8.2.5.1 Experimental Technique . . . . . . . . . 104

8.2.5.2 Scientific Goals of Line Profile Analysis . . . . . 104

8.2.5.3 Instrumental Broadening . . . . . . . . . 106

8.2.5.4 Crystal Size and Lattice Distortion - Separability 106

8.2.5.5 Separation According to WARREN-AVERBACH . 107

8.2.5.6 Matching Lattice Distortions and Structural Models 109

8.2.5.7 Classical WARREN-AVERBACH Separation . . . . 110

8.2.5.8 Separation After Peak Shape Modeling . . . . . . 114

8.2.6 Peaks in SAXS Patterns . . . . . . . . . . . . . . 117

8.3 No Peaks: The Interpretation of Diffuse Scattering . . . . . . . . . . 118

8.3.1 Intensity Level Between SAXS and WAXS: Electron Density Fluctuations . . . . . . . . . . . . . . . . 119

8.3.2 Intensity Decay Between SAXS and WAXS: PoROD's Law 121

8.3.3 SAXS: Fractal Structure . . . . . . . . . . . . . . 127

8.4 General Evaluation by Integration of Scattering Data . . . . . . . . 129

8.4.1 Azimuthal Averaging of Isotropic Scattering Patterns . . . . 129

8.4.2 Isotropization of Anisotropic Scattering Patterns . . . . . . 130

8.4.3 SAXS Projections ................ . . 132

8.4.3.1 Scattering Power (Invariant) . . . . . . . . . . . 132

8.4.3.2 1D Projections . . . . . . . . . . . . . . 135

8.4.3.3 2D Projections . . . . . . . . . . . . . 138

8.5 Visualization of Domain Topology from SAXS Data . . . . . . . . 138

8.5.1 Extraction of the Topological Information . . . . . . . . . . 139

8.5.2 1D Correlation Function Analysis . . . . . . . . . . . . . . 142

8.5.3 Isotropic Chord Length Distributions (CLD) . . . . . . . . 148

8.5.4 1D Interface Distribution Functions (IDF) . . . . . . . . . 150

8.5.5 Anisotropic Chord Distribution Functions (CDF) . . . . . . 152

8.5.5.1 Definition ............... 152

8.5.5.2 Computation of the CDF for Materials with Fiber Symmetry ................ 153

8.5.5.3 Relation Between a CDF and IDFs . . . . . . . . 154

8.5.5.4 How to Interpret a CDF . . . . . . . . . . 155

8.5.5.5 Semi-quantitative CDF Analysis. An Example . . 157

8.6 Biopolymers: Isotropic Scattering of Identical Uncorrelated Particles 161

8.7 Quantitative Analysis of Multiphase Topology from SAXS Data . . 163

8.7.1 Models for Uncorrelated Polydisperse Particles . . . . . . . 164

8.7.1.1 Polydisperse Layers and 1D Particles . . . . . . . 164

8.7.1.2 Uncorrelated Particles in 2D: Fibril Diameters in Fibers . . . . . . . . . . . . 165

8.7.1.3 Uncorrelated Polydisperse Homogeneous Spheres 169

8.7.1.4 Inhomogeneous Spherical Particles . . . . . . . . 170

8.7.2 Stochastically Condensed Structure . . . . . . . . . . . 171

8.7.3 Distorted Structure by Infinite 1D Arrangement . . . . . . . 175 
8.7.3.1 Construction of a 1D Paracrystal . . . . . . . 175

8.7.3.2 Application .................... 176

8.7.3.3 The Stacking Model . . . . . . . . . . . . . 178

8.7.3.4 The Lattice Model . . . . . . . . . . . . . . . . . 182

8.7.3.5 Model Fitting: Choice of Starting Values for the

Model Parameters . . . . . . . . . . . . . . 184

8.8 Nanostructures - Soft Materials with Long Range Order . . . . . . 185

8.8.1 Required Corrections of the Scattering Intensity . . . . . . . 185

8.8.2 $I_{1}(s)$ from a Nanostructured Layer System . . . . . . . . . 186

8.8.3 Typical Results . . . . . . . . . . . . . . . . . . . 187

8.9 Anomalous X-Ray Scattering . . . . . . . . . . . . . . . . 188

9 High but Imperfect Orientation 191

9.1 Basic Definitions Concerning Orientation . . . . . . . . . . . . . . 192

9.1.1 Pole Figures and Their Expansion . . . . . . . . . . . . . . 192

9.1.2 The Uniaxial Orientation Parameter $f_{\text {or }}$. . . . . . . . . . . 194

9.1.3 Character of Fiber-Symmetrical Orientation Distributions . 196

9.2 Observed Intensity and Oriented Intensity - The Relation . . . . . . 197

9.3 Desmearing by Use of a Master Orientation Distribution . . . . . . 197

9.4 F2: Double Fiber Symmetry - Simplified Integral Transform . . . . 198

9.5 F3: $g(\varphi)$ Shows Fiber Symmetry - Solution . . . . . . . . . . . . 200

9.6 Extraction of $g(\varphi)$ from Meridional or Equatorial Reflections . . . 200

9.6.1 Unimodal Meridional Reflection Intensity . . . . . . . . . . 200

9.6.2 Unimodal Equatorial Reflection Intensity . . . . . . . . . . 201

9.7 The Ruland Streak Method . . . . . . . . . . . . . . . . . . . . . . 201

9.8 Analytical Functions Wrapped Around Spheres: Shape Change . . . 205

10 Orientation Growing from the Isotropic State 209

10.1 Ruland's Theory of Affine Deformation . . . . . . . . . . . . . . 210

10.1.1 Overview . . . . . . . . . . . . . 210

10.1.2 Application ...................... 211

10.2 The MGZ Technique of Elliptical Coordinates . . . . . . . . . . . 213

11 Fitting Models to Data 217

11.1 Which Data Are Fitted? . . . . . . . . . . . . . . . . . . . 217

11.2 Which Techniques Are Applied? . . . . . . . . . . . . . . 218

$\begin{array}{ll}\text { References } & 221\end{array}$

$\begin{array}{ll}\text { Subject Index } & 229\end{array}$ 


\subsection{How to Collect Complete Scattering Patterns}

Resorting to Debye (cf. p. 1), "only a continuous scattering pattern can be the fundament of proper reasoning" the general question must be addressed, how a complete scattering pattern can be collected. The considerations of this section are based on the assumption that the scattering pattern is recorded by means of a 2D- or 1D-detector.

\subsubsection{Isotropic Scattering}

The Limits. There are a lot of materials whose scattering pattern does not change if the sample is deliberately rotated in the X-ray beam. Such materials are called isotropic. For isotropic materials completeness is only a question of the angular range in which significant scattering information is gathered. The technical limits are defined by the setup, and the fundamental parameter is the distance $R$ between sample and detector. The smallest accessible scattering angle is given by the size of the beam stop (cf. p. 37, Fig. 4.1b) which prevents the detector from being damaged by the direct beam. The highest angle with reasonable data is restricted by the extension of the detector or, worse, by the signal-to-noise $(\mathrm{S} / \mathrm{N})$ ratio of the data. If thin samples are exposed for short time in a weak beam, there is most probably no significant information in the outer part of the scattering pattern and quantitative data evaluation is futile. The problem is less severe if a 2D-detector is used. In this case azimuthal averaging will increase the $\mathrm{S} / \mathrm{N}$-ratio in particular at high scattering angles.

How to Arrange the Setup. In practice, the distance $R$ is long enough, if the scattering intensity can safely be extrapolated towards zero from the data recorded. The distance $R$ is short enough, if in the outer part of the scattering pattern, a sufficiently long region with a monotonous background is recorded. One should not underestimate the need for sufficient recording of background in SAXS and USAXS. In order to increase the highest accessible angle, 2D detectors may be placed in a lateral off-set position with respect to the primary beam.

If there is no possibility to cover the complete range with one detector, there may be the possibility to use two detectors which are placed in different distances from the sample. In the worst case the experiment has to be performed several times with different setups.

\subsubsection{Anisotropic Scattering}

Anisotropy is frequently observed in soft materials, but the symmetry of anisotropy is varying. Fibers and films show, in general, less complex anisotropy than ordinary or photonic crystals.

\subsubsection{Single Crystal Anisotropy}

Complete scattering patterns of samples with a complex "single-crystal" anisotropy can only be recorded in a texture setup (Chap. 9, Fig. 9.3). The samples must be rotated in order to scan the required fraction of reciprocal space. 


\subsubsection{Fiber Symmetry}

Definition. Fiber symmetry is uniaxial or cylindrical symmetry. Revolving the sample about the fiber axis does not change the scattering pattern, but tilting the sample with respect to the fiber axis does.

USAXS and SAXS. Concerning USAXS and SAXS, the scattering pattern that is recorded on a 2D detector is complete if the principal axis of the sample is set normal to the direction of the incident X-ray beam (primary beam). Completeness is a result of two facts.

1. Fiber symmetry: with the $s_{3}$ axis in fiber direction the pattern shows rotational symmetry in the plane $\left(s_{1}, s_{2}\right)$, thus $I(\mathbf{s})=I\left(\sqrt{s_{1}^{2}+s_{2}^{2}}, s_{3}\right)=I\left(s_{12}, s_{3}\right)$ is a function of $s_{3}$ and of the distance from this axis only.

2. The tangent plane approximation is valid: the curvature of the Ewald sphere is negligible at small scattering angles.

Thus in this favorable case the complete information on nanostructure is recorded in one 2D image. Mathematically the recorded image is a slice

$$
\lceil I(\mathbf{s})\rceil_{2}\left(s_{1}, s_{3}\right) \equiv I\left(s_{12}, s_{3}\right) .
$$

It is complete because of fiber symmetry. The 2D Fourier transform of this image is not related to the searched slice, but to a projection of the correlation function. In contrast, the sought-after slice in real space

$$
\begin{aligned}
\rho^{\star 2}\left(r_{12}, r_{3}\right) & =\left\lceil\rho^{\star 2}(\mathbf{r})\right]_{2}\left(r_{1}, r_{3}\right) \\
& =F^{2}\left(\{I(\mathbf{s})\}_{2}\left(s_{1}, s_{3}\right)\right),
\end{aligned}
$$

is the $2 \mathrm{D}$ Fourier transform of the projection

$$
\{I(\mathbf{s})\}_{2}\left(s_{1}, s_{3}\right)=\int I\left(\sqrt{s_{1}^{2}+s_{2}^{2}}, s_{3}\right) d s_{2}
$$

of the complete intensity from the 3D scattering pattern on the slice formed by the detector plane. Because of completeness it can be computed from the data collected in one $2 \mathrm{D}$ scattering pattern.

WAXS and MAXS. Fiber symmetry means that, even in WAXS and MAXS, the scattering pattern is completely described by a slice in reciprocal space that contains the fiber axis. Nevertheless, for $2 \theta>9^{\circ}$ the tangent plane approximation is no longer valid and the detector plane is mapped on a spherical surface in reciprocal space.

If we keep the sample's principal axis normal to the primary beam and record a scattering pattern, we can readily map the measured intensities to the plane that we need to know (BUerger (1942) in AleXANDER [7], p. 58-62). For this purpose 


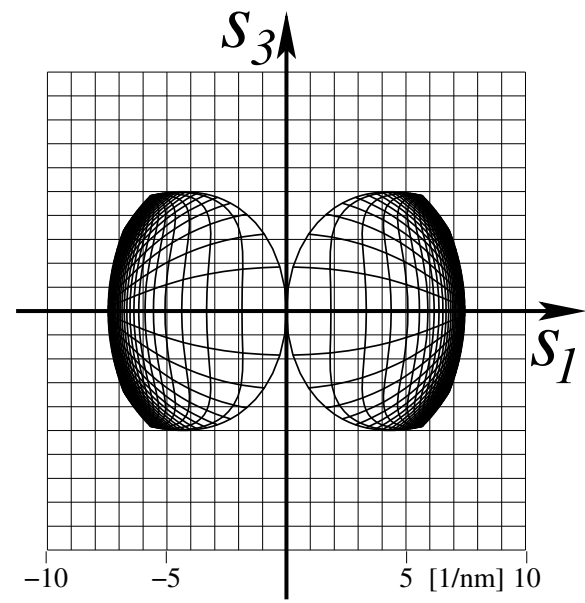

Figure 2.6. WAXS, 2D-detector and fiber symmetry: unwarping of the detector surface to map it on the $\left(s_{1}, s_{3}\right)$-slice. Fiber direction is normal to the primary beam. $R=10 \mathrm{~cm}, \lambda=$ $0.154 \mathrm{~nm}$. The warped grid in the sketch is a square grid on the detector (edge length: $3 \mathrm{~cm}$ )

we refer to Fig. 2.3 and deduce the out-of-plane component $s_{2}$, which is readily established by application of Pythagoras' cathetus theorem ${ }^{22}$. Thereafter we compute the components $s_{1}$ and $s_{3}$ and receive the mapping equations. The result shows a peculiar deformation (Fig. 2.6). With respect to the slice that contains the complete information, only the area enclosed by solid lines is recorded on the plane detector. There are two blind gusset-shaped areas extending from the center upward and downward along the meridian. Within these areas Bragg peaks may be hidden. Thus the scattering pattern of fibers collected on the 2D detector is not complete if WAXS data are recorded.

It is worth to be noted that not only the position of the pixels, but also their area is modified by the unwarping. Correction of WAXS images thus requires both a translation and a magnification of the intensity proportional to the inverse of the area enclosed by the respective vertices. After the advent of digital computers it became possible to carry out the cumbersome calculus automatically ${ }^{23}$, as proposed by FRASER ${ }^{24}$ et al. [35].

The solution to access the invisible areas is readily copied from texture analysis: tilt the sample by $\psi$ and receive 1 data point on the meridian that corresponds to $s_{3}=(2 / \lambda) \sin \psi$. The result of the mapping is shown in Fig. 2.7. Thus by recording a series of images taken at different tilt angles of the fiber the blind area can be covered to a sufficient extent. Finally, the remnant blind spots may be covered by means of

\footnotetext{
${ }^{22}\left(-2 s_{2} / \lambda=s^{2}\right.$ in the right triangle under THALES' circle whose leg is indicated by a dashed line). The use of the cathetus theorem was suggested by my daughter Agnes.

${ }^{23}$ A corresponding program was presented by RICHARD HILMER (DuPont Inc., Wilmington, USA) at a CCP13 workshop in 1997. The program is property of DuPont.

${ }^{24} \mathrm{~B}$. HSIAO and scientists of his group have started to call the algorithm "Fraser correction"
} 


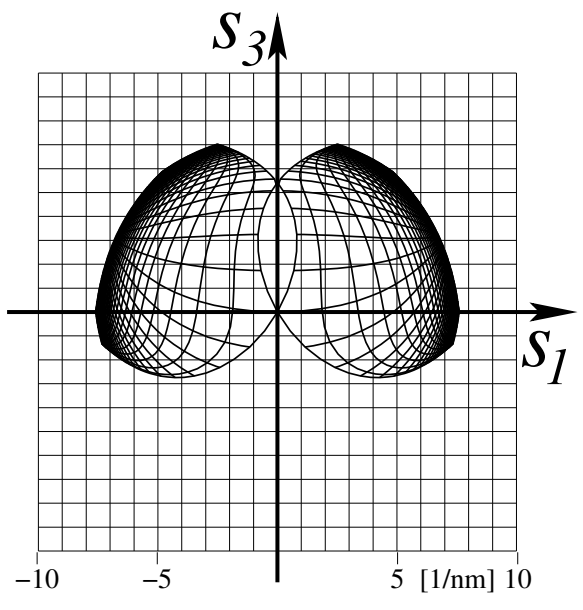

Figure 2.7. WAXS, 2D-detector and fiber symmetry: unwarping of the detector surface to map it on the $\left(s_{1}, s_{3}\right)$-slice. Fiber direction is tilted by $\psi=-30^{\circ}$ with respect to the primary beam. $R=10 \mathrm{~cm}, \lambda=0.154 \mathrm{~nm}$. On the detector the apparent warped grid is a square grid (edge length: $3 \mathrm{~cm}$ )

2D extrapolation procedures, e.g., the algorithm based on radial basis functions [36] which is implemented in $p v-$ wave ${ }^{\circledR}$ [37].

\subsection{Application of Digital Image Processing (DI)}

\subsubsection{DI and the Analysis of Scattering Patterns}

In 1994, when the bottleneck of scattering data analysis was still the poor performance of detectors, RUDOLPH \& LANDES were already spotting the bottleneck of our days:

"Having 2D detection that operates in the cycle time of key experiments means we are then potentially limited by image processing. In other words, as soon as we begin using 2D-detectors to measure patterns, we are forced to use image analysis methods to extract information from the images. With the rapid development of fast detectors, image analysis becomes key to our effective use of this technology.”( [38], p. 26)

The source code of a set of DI procedures for the processing of scattering patterns written for $p v$-wave is available on the worldwide web (www.chemie.unihamburg.de/tmc/stribeck/dl/). 


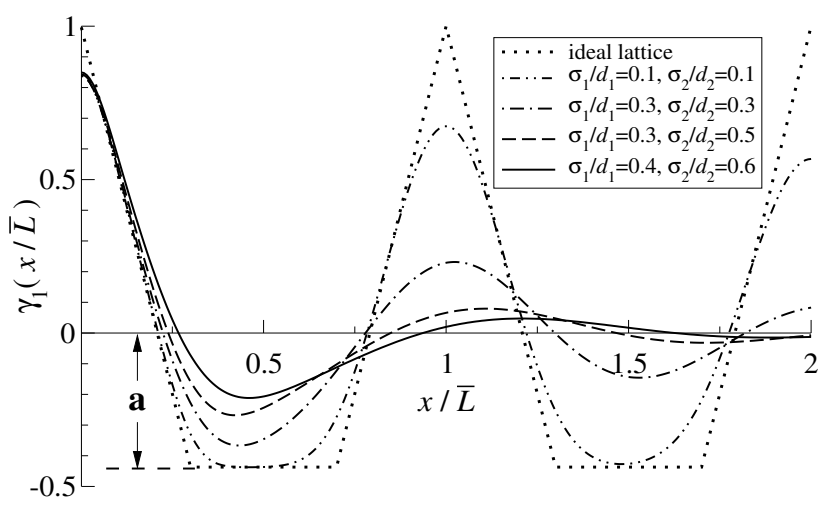

Figure 8.21. Features of a $1 D$ correlation function, $\gamma_{1}(x / \bar{L})$ for perfect and disordered topologies. $\bar{L}$ is the number-average distance of the domains from each other (i.e., long period). Dotted: Perfect lattice. Dashed and solid lines: Paracrystalline stacks with increasing disorder. $a=-v_{l_{1}} /\left(1-v_{l_{1}}\right)$ with $0<v_{l_{1}} \leq 0.5$ is a measure of the linear volume "crystallinity" in the material, which is either $v_{l_{1}}$ or $1-v_{l_{1}}$

the region of linear decay of the correlation function, i.e., in the so-called "autocorrelation triangle". The typical shape of such a correlation function for topologies with varying amount of disorder is sketched in Fig. 8.21. Obviously, the autocorrelation triangle of the ideal lattice (dotted curve) is not preserved in paracrystalline stacks of higher polydispersity. Thus, a simple linear extrapolation ("linear regression autocorrelation triangle”, LRAT [162]) will only yield reliable information concerning the properties of the idealized lattice from the real data, if the polydispersity remains rather low.

Analysis of the 1D Correlation Function. Several publications describe the search for a simple graphical analysis [22,159,162-164] of the 1D correlation function by means of a geometrical construction. It is the drawback of all such methods that polydispersity and heterogeneity are not considered. The methods are derived from the general generation principle of correlation functions (Fig. 8.20), resulting in equations (cf. Eqs. (8.23), (8.70) and (8.64)) for the first off-origin maximum, the depth of the first minimum or the initial slope $\gamma_{i d}^{\prime}(0)$ of ideal correlation functions. For the simplified case of a lamellar system we obtain

$$
\gamma_{1, i d}(x)=1-\frac{1}{\ell_{p_{1}}}|x|+\ldots
$$

with $\ell_{p_{1}}$ being the average chord length of the one-dimensional ideal two-phase topology with

$$
\frac{1}{\ell_{p_{1}}}=\frac{1}{\bar{d}_{1}}+\frac{1}{\bar{d}_{2}}
$$


$\bar{d}_{1}$ the average layer thickness of the first of the two kinds ${ }^{78}$ of lamellae, and $\bar{d}_{2}$ related to the second kind of layers. $\bar{L}=\bar{d}_{1}+\bar{d}_{2}$ is called the average ${ }^{79}$ long period. Without loss of generality we may restrict further discussion to linear crystallinities $^{80}$

$$
v_{l}=\frac{\bar{d}_{1}}{\bar{L}}
$$

with $v_{l} \leq 0.5$. The crystallinity is called "linear" in order to distinguish it from the overall volume crystallinity in the sample, because $v_{l}$ does not account for the presence of extended domains (of matrix material) outside the scattering entities. From Eqs. (8.64) and (8.65) we obtain for the zero of the initial slope of the ideal correlation function

$$
\begin{aligned}
x_{0} & =\frac{\bar{d}_{1} \bar{d}_{2}}{\bar{d}_{1}+\bar{d}_{2}} \\
& =v_{l}\left(1-v_{l}\right) \bar{L} .
\end{aligned}
$$

Figure 8.21 shows model functions both for ideal and realistic cases. The dotted curve demonstrates the case of the ideal and infinitely extended 1D lattice. Here every time the ghost is displaced by an integer multiple of the lattice constant $(x / L=$ $1,2,3, \ldots)$, the correlation returns to the ideal value 1 . For the 1D lattice not only $x_{0}$, but also the valley depths

$$
\gamma_{1, \min }=a=-\frac{v_{l}}{1-v_{l}}
$$

are related to the composition ${ }^{81}, v_{l}\left(1-v_{l}\right)$, of the material (see also p. 133, Fig. 8.15). The common graphical evaluation methods try to transfer these features of the ideal correlation function of an ideal lattice to real correlation functions of polydisperse soft matter that are computed from experimental data. The valley-depth method has first been devised by VONK [159]: whenever a flat minimum is found in a real correlation function, the distortion is weak and the linear crystallinity can significantly be determined from the properly normalized correlation function by application of Eq. (8.68).

In practice, the observed distortion is frequently strong. Thus, the correlationfunction minimum is not flat. This is demonstrated in most of the dashed and solid curves in Fig. 8.21. They show model correlation functions of the paracrystalline stacking model with varying amount of disorder. Computation ${ }^{82}$ is based on Eq. (8.104), p. 180.

\footnotetext{
${ }^{78}$ For instance the "amorphous", "hard", "crystalline", ...

${ }^{79}$ Speaking of averages and denoting symbols by an overbar already means a generalization for distorted structures which will be discussed later.

${ }^{80}$ Again, "crystallinity" may be replaced by "hard phase fraction", "soft phase fraction", or whatever designation applies better to the material that is studied.

${ }^{81}$ Conceded - Eq. (8.68) violates Babinet's theorem. Nevertheless, it is valid for $v_{1} \leq 0.5$ and can easily be remembered, whereas the correct equation is somewhat more involved.

${ }^{82}$ It is convenient to set $A_{P_{1}}=1, \bar{L}=\bar{d}_{1}+\bar{d}_{2}=1$. Rounding errors are suppressed by replacing the intensity by $1 / s^{2}$ (POROD's law) for big arguments $(s>8)$. A smooth phase transition zone (in all the example curves: $\left.d_{z}=0.1\right)$ is considered by multiplication with $\exp \left(-\left(2 \pi s d_{z} / 3\right)^{2}\right)$. From this one-dimensional scattering intensity the correlation function is obtained by Fourier transformation.
} 
Figure 8.21 shows functions of the distorted topologies that are not pointed at the origin, and $\gamma_{1}(0)<1$. The reason is that the presented model is not an ideal two-phase system, because it considers smooth transitions of the electron density between the "crystalline" and the "amorphous" layers.

In practice, even a more severe damping of the correlation function close to the origin is frequently accepted in order to compute the correlation function with little effort of evaluation [159]: POROD's law is not evaluated (cf. p. 124, Fig. 8.11), and thus the Fourier integral cannot be extended to infinity. Instead, the position $s_{\min }$ in the scattering curve is determined at which the SAXS intensity is lowest. This level is subtracted, and the integral is only extended up to $s_{\min }$.

The case of low distortion is shown in the dashed-dotted-dotted curve from Fig. 8.21. The first minimum still reaches the ideal valley depth. Therefore it is still possible to determine the linear composition of the material from Eq. (8.68).

Let us discuss the first off-origin maximum of $\gamma_{1}(x / \bar{L})$. For the ideal lattice and weakly distorted materials the maximum is found at the position of the numberaverage long period, $\bar{L}$, i.e. at $x / \bar{L}=1$. This is not the case for structures that are distorted more severely. Thus a long period, $\bar{L}_{a p p}$, determined from the position of the first maximum in $\gamma_{1}(x)$ is only an apparent one, and it is always overestimated [130]. An overestimation of $20 \%\left(\bar{L}_{a p p} \approx 1.2 \bar{L}\right)$ is not unusual.

The First-Zero Method of Correlation Function Analysis. For the purpose of a practical graphical evaluation of the linear crystallinity, Eq. (8.67) can be applied to a renormalized correlation function $\gamma_{1}\left(x / \bar{L}_{a p p}\right)$. The method which has been proposed by Goderis et al. [162] is based on the implicit assumption that the first zero, $x_{0}$, of the real correlation function is shifted by the same factor as is the position of its first maximum, $\bar{L}_{a p p}$.

The idea is already described in the first paper of VONK and KORTLEVE ([159], p. 22) as a method to retrieve fit parameters. In their second paper ([160], p. 128) the authors state that inaccurate values are returned, if the found linear crystallinity is between 0.35 and 0.65 .

The general inferiority of geometrical construction methods $[162,163]$ as compared to more involved methods which consider polydispersity has first been demonstrated by SANTA CRUZ et al. [130], and later in many model calculations by CRIST [165-167]. Nevertheless, in particular the first-zero method is frequently used. Thus, it appears important to assess its advantages as well as its limits. Validation can be carried out by graphical evaluation of model correlation functions [130,165].

If the statistical model of a paracrystalline stack is assumed, it turns out that the renormalization attenuates the influence of polydispersity on the position of the first zero. In general, the first-zero method is more reliable than the valley-depth method, although it is not perfect. Even the first-zero method is overestimating the value of $v_{l}$. The deviation is smaller than 0.05 , if the found crystallinity is smaller than 0.35 . If bigger crystallinities are found, the significance of the determination is 


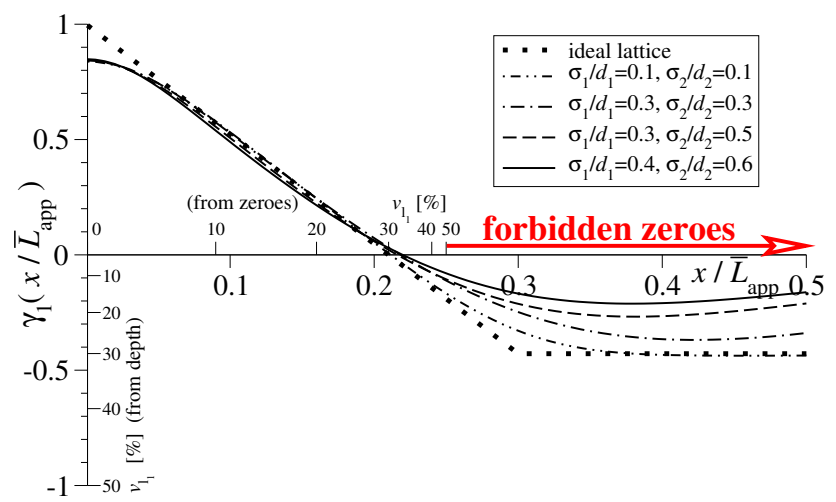

Figure 8.22. Testing the first-zero method for the determination of the linear crystallinity, $v_{l}$, from the linear correlation function, $\gamma_{1}\left(x / \bar{L}_{a p p}\right)$ with $\bar{L}_{a p p}$ being the position of the first maximum in $\gamma_{1}(x)$ (not shown here - but cf. Fig. 8.21). Model tested: Paracrystalline stacking statistics with Gaussian thickness distributions. The interval of forbidden zeroes is shown. An additional horizontal non-linear axis permits to determine the linear crystallinity directly. A corresponding vertical axis shows the variation of the classical "valley-depth method"

rapidly breaking down, and an individual demonstration of the error of determination becomes essential. In practice, insignificance can no longer be overlooked, if Eq. (8.69) applied to measured data does not return real solutions ("forbidden zeroes" in Fig. 8.22).

If the initial part of the correlation function exhibits significant deviations from a straight line, the proposers of the first-zero method recommend to carry out a linear regression (LRAT) [162] on the autocorrelation triangle. The problem of doing so is demonstrated in Fig. 8.21 and its discussion. Moreover, if the initial part of the correlation function does not only show a monotonous decay but discrete features, this is a strong indication of a topology that is not only polydisperse, but also heterogeneous $^{83}$. In this case, a graphical correlation function analysis of isotropic data is of little significance anyway, and the study of uniaxially oriented material is recommended. Analysis may be performed by means of the CDF method (cf. Sect 8.5.5). If a low-noise scattering curve from isotropic material is at hand, it may be possible to separate components of a heterogeneous nanostructure by means of the IDF method (cf. Sect. 8.5.4) combined with model fits.

The first-zero method starts from the ideal lattice and Eq. (8.67). For the purpose of evaluation of scattering curves from polydisperse soft matter the ideal long period, $\bar{L}$, is replaced by $\bar{L}_{a p p}$, i.e. the validity of $\gamma_{1}\left(v_{l}\left(1-v_{l}\right) \bar{L}_{a p p}\right)=0$ is assumed. Because of the fact that the zero of a function is determined, not even a normalization of $\gamma_{1}(x)$ is required [162]. Figure 8.22 displays the model data of Fig. 8.21 after the methodinherent renormalization $x \rightarrow x / \bar{L}_{\text {app }}$. Comparison with Fig. 8.21 shows that now

\footnotetext{
${ }^{83}$ No infinitely extended layers, several components with different topology (e.g. primary and secondary lamellar stacks)
} 
the zeroes of the correlation functions with varying polydispersity are found close to the correct value $x_{0} / \bar{L}_{a p p}=0.21=0.3(1-0.3)$. Vice versa, a good estimate for the linear crystallinity is obtained from the pair of roots which solve the quadratic relation

$$
\frac{x_{0}}{\bar{L}_{a p p}}=v_{l_{c}}\left(1-v_{l_{c}}\right) \text {. }
$$

If other statistical models of polydispersity should prove more appropriate than the paracrystalline stack, validations of the first-zero method may be carried out in analogy to the one presented here.

For anisotropic scattering patterns and the multidimensional case VONK ( [168] and [22], p. 302) has proposed to utilize a multidimensional correlation function. It is not frequently applied.

\subsubsection{Isotropic Chord Length Distributions (CLD)}

The isotropic chord length distribution (CLD) is of limited practical value if soft matter with only short-range order is studied. Nevertheless, the related notions have been fruitful for the development of new methods for topology visualization from SAXS data.

Related Notions. Not only the 1D correlation function, but also the general 3D correlation function starts with a linear decay, and its series expansion

$$
\gamma(r)=1-\frac{|r|}{\ell_{p}}+\ldots
$$

was already given by POROD [18]. $\ell_{p}$ is the average chord length that has already been introduced on p. 112 in Eq. (8.23). Starting from this relation MÉRING and TCHOUBAR $[118,141,169,170]$ have derived that even the distributions of the individual segment lengths can be visualized by evaluation of an isotropic scattering pattern. They make use of the derivation theorem (p. 23, Eq. 2.39) applied to deliberate slicing directions of the structure and apply it twice. The two derivatives are distributed on each of the factors of the autocorrelation, $\Delta \rho^{* 2}(r)$, and an ideal edge enhancement is accomplished. The result shows that the second radial derivative of the radial correlation function

$$
\gamma^{\prime \prime}(r)=\frac{1}{\ell_{p}}(-2 \delta(r)+g(r)+g(-r))
$$

is formed by two images of a chord length distribution (CLD), $g(r)$ and a $\delta$ distribution at the origin (Fig. 8.23). The CLD is made from an infinite series of segment distributions that starts with the homo-segment distributions, $\ell_{1}(r)$ and $\ell_{2}(r)$, for the domains of phase 1 and 2 , respectively ${ }^{84}$, followed by the di-segment distributions of the long periods, $-2 \ell_{12}(r)$, and further out by the multi-segment distributions which describe the long-range arrangement of the particles in the material.

\footnotetext{
${ }^{84}$ Shape and size of the domains make these distributions.
} 


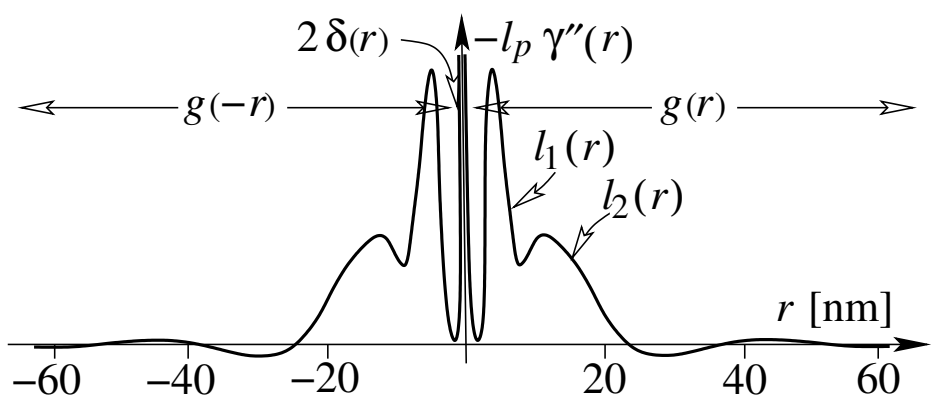

Figure 8.23. The chord length distributions $g(r)$ and $g(-r)$ found in the 2nd derivative $\gamma^{\prime \prime}(r)$ of the radial correlation function. The example shows $g(r)$ of a suspension of $10 \mathrm{wt} . \%$ of silica (reproduced from a handout of DENISE TCHOUBAR)

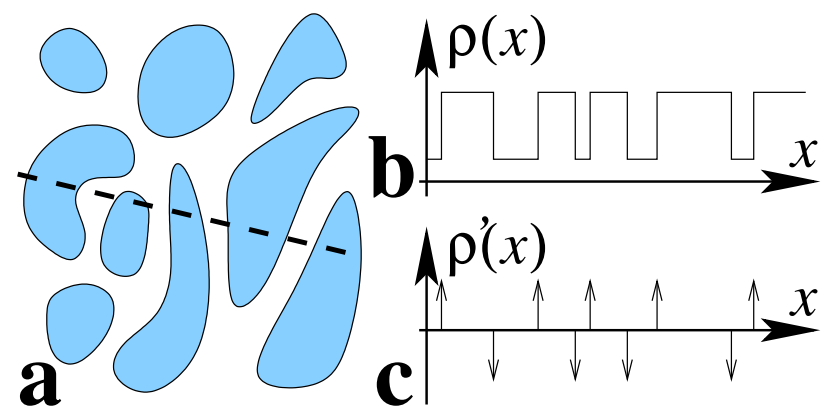

Figure 8.24. Demonstration of the edge-enhancement principle built into the chord length distribution. (a) Two-phase structure intersected by a straight line. (b) The density along the line. (c) The derivative of the density is a sequence of $\delta$-functions which are marking the positions of the domain edges

In the sketch taken from a handout of TCHOUBAR the distributions $\ell_{1}(r)$ and $\ell_{2}(r)$ are separated extraordinarily well.

The relation between structure and the chord distributions is readily established from considerations of topological density functions along a straight line traversing the material (Fig. 8.24). In Fig. 8.24a the respective sequence of chords is indicated. Figure $8.24 \mathrm{~b}$ is a sketch of the corresponding density function, $\rho(x)$. Its first derivative, $\rho^{\prime}(x)$ (Fig. 8.24c), is nothing but a sequence of $\delta$-functions put at the positions of the domain edges. Thus the edges are enhanced, and the autocorrelation $-\rho^{\prime}(x) \star \rho^{\prime}(-x)=g_{p}(x)$ is the partial CLD for the chosen special path through the topology.

For a general, isotropic and condensed multiphase material with short-range order, the CLD offers the best possible model-free visualization of the nanostructure. Nevertheless, the image does not show many details because of the inherent solidangle average. 


\section{References}

[1] Debye P, Menke H (1931) Erg techn Röntgenkunde 2:1

[2] Stribeck N (2006) J Appl Cryst 39:237

[3] Fedorova IS, Schmidt PW (1978) J Appl Cryst 11:405

[4] Abramowitz M, Stegun IA (eds.) (1968) Handbook of Mathematical Functions. Dover Publications, New York

[5] Hosemann R, Bagchi SN (1962) Direct Analysis of Diffraction by Matter. North-Holland, Amsterdam

[6] Guinier A (1963) X-Ray Diffraction. Freeman, San Francisco

[7] Alexander LE (1979) X-Ray Diffraction Methods in Polymer Science. Wiley, New York

[8] Ruland W (1964) Br J Appl Phys 15:1301

[9] Ruland W, Smarsly B (2002) J Appl Cryst 35:624

[10] Elsner G, Riekel C, Zachmann HG (1984) In: Kausch HH, Zachmann HG (eds.), Advances in Polymer Science, vol. 67, pp. 1-58, Springer, Berlin

[11] Kirfel A, Eichhorn K (1990) Acta Cryst A46:271

[12] Kahn R, Fourme R, Gadet A, Janin J, Dumas C, André D (1982) J Appl Cryst $15: 330$

[13] Macgillavry CH, Rieck GD (eds.) (1968) International Tables for X-ray Crystallography, vol. 2. Physical and Chemical Tables. The Kynoch Press, Birmingham

[14] Ruland W (1961) Acta Cryst 14:1180

[15] Weisstein EW (1999), Fourier Transform. From MathWorld - A Wolfram Web Resource. http://mathworld.wolfram.com/FourierTransform.html

[16] Bonart R (1966) Kolloid Z u Z Polymere 211:14

[17] Debye P, Bueche AM (1949) J Appl Phys 20:518

[18] Porod G (1951) Colloid Polym Sci 124:83

[19] Brychkov YA, Glaeske HJ, Prudnikov AP, Tuan VK (1992) Multidimensional integral transformations. Gordon \& Breach, Philadelphia

[20] Burger C, Ruland W (2001) Acta Cryst A57:482

[21] Schmidt PW, Brill L. O (1967) In: Rowell RR, Stein RS (eds.), Electromagnetic Scattering. Proceedings of ICES 2, Amherst, MA, June 1965, pp. 169186, Gordon \& Breach, New York

[22] Baltá Calleja FJ, Vonk CG (1989) X-Ray Scattering of Synthetic Polymers. Elsevier, Amsterdam

[23] Conner WC, Webb SW, Spanne P, Jones KW (1990) Macromolecules 23:4742

[24] Schroer CG, Kuhlmann M, Roth SV, Gehrke R, Stribeck N, Almendarez Camarillo A, Lengeler B (2006) Appl Phys Lett 88:164102

[25] Spontak RJ, Williams MC, Agard DA (1988) Polymer 29:387

[26] Stribeck N (2001) J Appl Cryst 34:496

[27] Stokes AR (1948) Proc Phys Soc 61:382

[28] Warren BE, Averbach BL (1950) J Appl Phys 21:595

[29] Warren BE, Averbach BL (1952) J Appl Phys 23:497

[30] Ruland W (1969) J Polym Sci Part C 28:143 
[31] Perret R, Ruland W (1969) J Appl Cryst 2:209

[32] Ruland W (1968) J Appl Cryst 1:90

[33] Perret R, Ruland W (1970) J Appl Cryst 3:525

[34] Thünemann AF, Ruland W (2000) Macromolecules 33:1848

[35] Fraser RD, Macrae TP, Miller A, Rowlands RJ (1976) J Appl Cryst 9:81

[36] Buhmann MD (2000) Acta Numerica 9:1

[37] VNI, pv-wave manuals. V 7.5 (2001), Boulder, Colorado

[38] Rudolf PR, Landes BG (1994) Spectroscopy Eugene Oreg 9:22

[39] Hammersley AP, FIT2D V12.012 Reference Manual. http://www.esrf.fr/computing/scientific/FIT2D/

[40] RSI, Interactive Data Language IDL. V 6.1 (2004), Boulder, Colorado

[41] Rasband W, ImageJ - Image processing and analysis in Java. http://rsb.info.nih.gov/ij/

[42] Haberäcker P (1989) Digitale Bildverarbeitung. Hanser, München

[43] Stribeck N, Buchner S (1997) J Appl Cryst 30:722

[44] Riekel C, Engström P (1995) Nuclear Instr Meth Phys Res B97:224

[45] Müller M, Czihak C, Vogl G, Fratzl P, Schober H, Riekel C (1998) Macromolecules 31:3953

[46] Waigh TA, Donald AM, Heidelbach F, Riekel C, Gidley MJ (1999) Biopolymers 49:91

[47] Assouline E, Wachtel E, Grigull S, Lustiger A, Wagner HD, Marom G (2001) Polymer 42:6231

[48] Dreher S, Zachmann HG, Riekel C, Engstrøm P (1995) Macromolecules 28:7071

[49] Heidelbach F, Riekel C, Wenk HR (1999) J Appl Cryst 32:841

[50] Wang YD, Cakmak M (2001) Polymer 42:4233

[51] Loidl D, Paris O, Burghammer M, Riekel C, Peterlik H (2005) Phys Rev Lett 95:225501

[52] Stribeck N, Almendarez Camarillo A, Nöchel U, Schroer C, Kuhlmann M, Roth SV, Gehrke R, Bayer RK (2006) Macromol Chem Phys 207:1239

[53] Bark M, Zachmann HG (1993) Acta Polym 44:259

[54] Wutz C, Bark M, Cronauer J, Döhrmann R, Zachmann H (1995) Rev Sci Instrum 66:1303

[55] Kolb R, Seifert S, Stribeck N, Zachmann HG (2000) Polymer 41:1497

[56] Stribeck N, Almendarez Camarillo A, Cunis S, Bayer RK, Gehrke R (2004) Macromol Chem Phys 205:1445

[57] Stribeck N, Bayer R, Bösecke P, Almendarez Camarillo A (2005) Polymer 46:2579

[58] Casselyn M, Finet S, Tardieu A, Delacroix H (2002) Acta Cryst D58:1568

[59] Rössle M, Panine P, Urban VS, Riekel C (2004) Biopolymers 74:316

[60] Weiss TM, Narayanan T, Wolf C, Gradzielski M, Panine P, Finet S, Helsby WI (2005) Phys Rev Lett 94:038303

[61] Burger HC, van Cittert PH (1932) Z Phys 79:722

[62] Heikens D (1959) J Polym Sci 35:139

[63] Porod G (1961) Fortschr Hochpolym Forsch 2:363 
[64] DuMond JWM (1947) Phys Rev 72:83

[65] Guinier A, Fournet G (1955) Small-Angle Scattering of X-Rays. Chapman and Hall, London

[66] Ruland W (1977) Colloid Polym Sci 255:417

[67] Ruland W (1978) Colloid Polym Sci 256:932

[68] Glatter O (1974) J Appl Cryst 7:147

[69] Wiegand W, Ruland W (1979) Colloid Polym Sci 257:449

[70] Stribeck N (1996) Macromolecules 29:7217

[71] Schelten J, Hendricks RW (1975) J Appl Cryst 8:421

[72] Pedersen JS (2004) J Appl Cryst 37:369

[73] Schuster M, Göbel H (1995) J Phys D Appl Phys 28:A270

[74] Schuster M, Göbel H (1996) J Phys D Appl Phys 29:1677

[75] Müller-Buschbaum P, Roth SV, Burghammer M, Diethert A, Panagiotou P, Riekel C (2003) Europhys Lett 61:639

[76] Lengeler B, Tümmler J, Snigirev A, Snigireva I, Raven C (1998) J Appl Phys $84: 5855$

[77] Schroer CG, Kuhlmann M, Lengeler B, Günzler TF, Kurapova O, Benner B, Rau C, Simionovici AS, Snigirev AA, Snigireva I (2002) Proc SPIE 4783:10

[78] Hendrix J (1984) In: Kausch HH, Zachmann HG (eds.), Advances in Polymer Science, vol. 67, pp. 59-98, Springer, Berlin

[79] Wilson KS (1998) Nature Struct Biol 5:627

[80] Stribeck N (2003) Anal Bioanal Chem 376:608

[81] Luzzati V (1957) Acta Cryst 10:643

[82] Perret R, Ruland W (1971) J Appl Cryst 4:444

[83] Ruland W, Tompa H (1972) J Appl Cryst 5:1

[84] Ruland W, Smarsly B (2004) J Appl Cryst 37:575

[85] Klug HP, Alexander LE (1974) X-Ray Diffraction Procedures for Polycrystalline and Amorphous Materials. 2nd edn., John Wiley \& Sons, New York

[86] Feigin LA, Svergun DI (1987) Structure Analysis by Small-Angle X-Ray and Neutron Scattering. Plenum Press, New York

[87] Kratky O, Porod G, Kahovec L (1951) Z Elektrochemie 55:53

[88] Perret R, Ruland W (1972) J Appl Cryst 5:116

[89] Polizzi S, Stribeck N, Zachmann HG, Bordeianu R (1989) Colloid Polym Sci 267:281

[90] Bösecke P, Diat O (1997) J Appl Cryst 30:867

[91] Orthaber D, Bergmann A, Glatter O (2000) J Appl Cryst 33:218

[92] Stribeck N, Ruland W (1978) J Appl Cryst 11:535

[93] Wendorff JH, Fischer EW (1973) Colloid Polym Sci 251:876

[94] Rathje J, Ruland W (1976) Colloid Polym Sci 254:358

[95] Wiegand W, Ruland W (1979) Progr Colloid Polym Sci 66:355

[96] Hermans PH, Heikens D, Weidinger A (1959) J Polym Sci 35:145

[97] Warren BE (1990) X-Ray Diffraction. Dover, New York

[98] Blake FC (1933) Rev Mod Phys 5:169

[99] Girard E, Legrand P, Roudenko O, Roussier L, Gourhant P, Gibelin J, Dalle D, Ounsy M, Thompson AW, Svensson O, Cordier MO, Robin S, Quiniou R, 
Steyer JP (2006) Acta Cryst D62:12

[100] Glocker R (1971) Materialprüfung mit Röntgenstrahlen. 5th edn., Springer, Berlin

[101] Glatter O, Kratky O (eds.) (1982) Small Angle X-ray Scattering. Academic Press, London

[102] Macgillavry CH, Rieck GD (eds.) (1968) International Tables for X-Ray Crystallography, vol. III. Kynoch Press, Birmingham

[103] Wang ZG, Hsiao BS, Sirota EB, Srinivas S (2000) Polymer 41:8825

[104] Bras W, Dolbnya I, Detollenaere D, van Tol R, Malfois M, Greaves G, Ryan A, Heeley E (2003) J Appl Cryst 36:791

[105] Liu J, Geil PH (1997) J Macromol Sci Phys B36:61

[106] Stribeck N, Wutz C (2001) J Polym Sci Part B Polym Phys 39:1749

[107] Brandrup J, Immergut EH, Grulke EA, Abe A, Bloch DR (eds.) (1999) Polymer Handbook. 4th edn., John Wiley \& Sons, New York

[108] Vonk CG (1973) J Appl Cryst 6:148

[109] Prosa TJ, Moulton J, Heeger AJ, Winokur MJ (1999) Macromolecules 32:4000

[110] Krenzer E, Ruland W (1981) Colloid Polym Sci 259:405

[111] Wcislak L, Klein H, Bunge HJ, Garbe U, Tschentscher T, Schneider JR (2002) J Appl Cryst 35:82

[112] Dehlinger U, Kochendörfer A (1939) Z Kristallograf 101:134

[113] Kochendörfer A (1939) Z Kristallograf 101:149

[114] Kochendörfer A (1944) Z Kristallograf 105:393

[115] Kochendörfer A (1944) Z Kristallograf 105:438

[116] Zernike F, Prins JA (1927) Z Phys 41:184

[117] Hosemann R (1962) Polymer 3:349

[118] Tchoubar D, Méring J (1969) J Appl Cryst 2:128

[119] Blöchl G, Bonart R (1986) Makromol Chem 187:1525

[120] van Berkum JGM, Vermeulen AC, Delhez R, de Keijser TH, Mittemeijer EJ (1994) J Appl Cryst 27:345

[121] Buchanan DR, Miller RL (1966) J Appl Phys 37:4003

[122] Warren BE (1941) J Appl Phys 12:375

[123] Hall WH (1949) Proc Phys Soc A62:741

[124] Ruland W (1965) Acta Cryst 18:581

[125] Stribeck N (1993) Colloid Polym Sci 271:1007

[126] Stribeck N (1993) J Phys IV 3:507

[127] Bonart R, Hosemann R, McCullough RL (1963) Polymer 4:199

[128] Hermans JJ (1944) Rec Trav Chim Pays Bas 63:211

[129] Hosemann R, Wilke W (1964) Faserforsch Textiltechnik 15:521

[130] Santa Cruz C, Stribeck N, Zachmann HG, Baltá Calleja FJ (1991) Macromolecules 24:5980

[131] Perret R, Ruland W (1971) Colloid Polym Sci 247:835

[132] Ruland W (1971) J Appl Cryst 4:70

[133] Ruland W (1975) Progr Colloid Polym Sci 57:192

[134] Vonk CG (1973) J Appl Cryst 6:81 
[135] Koberstein JT, Morra B, Stein RS (1980) J Appl Cryst 13:34

[136] Higgins JS, Benoît HC (1994) Polymers and Neutron Scattering. Clarendon Press, Oxford

[137] Porod G (1952) Colloid Polym Sci 125:51

[138] Jánosi A (1983) Monatsh f Chemie 114:377

[139] Stribeck N (2000) ACS Symp Ser 739:41

[140] Ruland W (1987) Macromolecules 20:87

[141] Méring J, Tchoubar D (1968) J Appl Cryst 1:153

[142] Wolff T, Burger C, Ruland W (1994) Macromolecules 27:3301

[143] Pfeifer P, Ehrburger-Dolle F, Rieker TP, T. GM, Hoffman WP, MolinaSabio M, Rodríguez-Reinoso F, Schmidt PW, Voss DJ (2002) Phys Rev Lett $88: 11502$

[144] Schmidt PW (1991) J Appl Cryst 24:414

[145] Rudin SA (1999) In: Weber Robert L.; Mendoza E (ed.), A Random Walk in Science, pp. 98-99, Inst. of Physics, London

[146] Avnir D, Biham O, Lidar D, Malcai O (1998) Science 279:39

[147] Ruland W (2001) Carbon 39:323

[148] Desper CR, Stein RS (1967) J Polym Sci Part B Polym Lett 5:893

[149] Jánosi A (1986) Z Phys B 63:383

[150] Blundell DJ (1978) Polymer 19:1258

[151] Barnes JD, Kolb R, Barnes K, Nakatani AI, Hammouda B (2000) J Appl Cryst 33:758

[152] Barnes JD, Bras W (2003) J Appl Cryst 36:664

[153] Stribeck N (2002) Colloid Polym Sci 280:254

[154] Press WH, Teukolsky SA, Vetterling WT, Flannery BP (1992) Numerical Recipes. Cambridge University Press, Cambridge

[155] Flores A, Pietkiewicz D, Stribeck N, Roslaniec Z, Baltá Calleja FJ (2001) Macromolecules 34:8094

[156] Claver Jr. GC, Buchdahl R, Miller RL (1956) J Polym Sci 20:202

[157] Peterlin A (1972) Text Res J 42:20

[158] Hosemann R (1949) Z Phys 127:16

[159] Vonk CG, Kortleve G (1967) Colloid Polym Sci 220:19

[160] Kortleve G, Vonk CG (1968) Colloid Polym Sci 225:124

[161] Duhamel P, Hollman H (1984) Electronics Letters 20:14

[162] Goderis B, Reynaers H, Koch MHI, Mathot VBF (1999) J Polym Sci Part B Polym Phys 37:1715

[163] Strobl GR, Schneider M (1980) J Polym Sci Part B Polym Phys B18:1343

[164] Vonk CG, Pijpers AP (1985) J Polym Sci Part B Polym Phys 23:2517

[165] Crist B (2000) J Macromol Sci Phys B39:493

[166] Crist B (2001) J Polym Sci Part B Polym Phys 39:2454

[167] Crist B (2003) Macromolecules 36:4880

[168] Vonk CG (1979) Colloid Polym Sci 257:1021

[169] Méring J, Tchoubar-Vallat D (1965) C R Acad Sc Paris 261:3096

[170] Méring J, Tchoubar-Vallat D (1966) C R Acad Sc Paris 262:1703

[171] Stribeck N (1992) Colloid Polym Sci 270:9 
[172] Stribeck N (1980) Computation of the Lamellar Nanostructure of Polymers by Computation and Analysis of the Interface Distribution Function from the Small-Angle X-ray Scattering. Ph.D. thesis, Phys. Chem. Dept., University of Marburg, Germany

[173] Stribeck N, Fakirov S, Sapoundjieva D (1999) Macromolecules 32:3368

[174] Stribeck N, Fakirov S (2001) Macromolecules 34:7758

[175] Fronk W, Wilke W (1985) Colloid Polym Sci 263:97

[176] Wilke W, Bratrich M (1991) J Appl Cryst 24:645

[177] Stribeck N, Buzdugan E, Ghioca P, Serban S, Gehrke R (2002) Macromol Chem Phys 203:636

[178] Stribeck N, Bayer R, von Krosigk G, Gehrke R (2002) Polymer 43:3779

[179] Barbi V, Funari SS, Gehrke R, Scharnagl N, Stribeck N (2003) Macromolecules 38:749

[180] Barbi V, Funari SS, Gehrke R, Scharnagl N, Stribeck N (2003) Polymer 44:4853

[181] Stribeck N, Androsch R, Funari SS (2003) Macromol Chem Phys 204:1202

[182] Stribeck N, Fakirov S, Apostolov AA, Denchev Z, Gehrke R (2003) Macromol Chem Phys 204:1000

[183] Stribeck N, Funari SS (2003) J Polym Sci Part B Polym Phys 41:1947

[184] Stribeck N (2004) Macromol Chem Phys 205:1455

[185] Stribeck N, Almendarez Camarillo A, Bayer R (2004) Macromol Chem Phys 205:1463

[186] Stribeck N, Bösecke P, Bayer R, Almendarez Camarillo A (2005) Progr Coll Polym Sci 130:127

[187] Brumberger H (ed.) (1995) Modern Aspects of Small-Angle Scattering, vol. 451 of NATO ASI Series, Series C. Kluwer, Dordrecht

[188] Svergun DI, Koch MHJ (2003) Rep prog phys 66:1735

[189] Vonk CG (1976) J Appl Cryst 9:433

[190] Glatter O (1977) J Appl Cryst 10:415

[191] Glatter O (1979) J Appl Cryst 12:166

[192] Letcher JH, Schmidt PW (1966) J Appl Phys 37:649

[193] Debye P (1915) Ann Phys 46:809

[194] Petoukhov MV, Svergun DI (2003) J Appl Cryst 36:540

[195] Svergun DI, Petoukhov MV, Koch MHJ (2001) Biophys J 80:2946

[196] Konarev PV, Volkov VV, Sokolova AV, Koch MHJ, Svergun DI (2003) J Appl Cryst 36:1277

[197] Stribeck N (1989) Colloid Polym Sci 267:301

[198] Statton WO (1962) J Polym Sci 58:205

[199] Statton WO (1968) Z Kristallogr 127:229

[200] Stribeck N (1999) J Polym Sci Part B Polym Phys 37:975

[201] Cohen Y, Thomas EL (1987) J Polym Sci Part B Polym Phys B25:1607

[202] Titchmarsh EC (1948) Introduction to the Theory of Fourier Integrals. Clarendon Press, Oxford

[203] Marichev OI (1983) Handbook of Integral Transforms of Higher Transcendental Functions. Ellis Horwood Ltd., Chichester 
[204] Schmidt PW (1967) J Math Phys 8:475

[205] Wolfram-Research (2005) Mathematica. Version 5.2. Wolfram Research, Inc., Champaign, Illinois

[206] Porod G (1972) Monatsh Chem 103:395

[207] Förster S, Burger C (1998) Macromolecules 31:879

[208] Kilian HG, Wenig W (1974) J Macromol Sci Phys B9:463

[209] Schultz JM, Lin JS, Hendricks RW (1978) J Appl Cryst 11:551

[210] Schultz JM, Fischer EW, Schaumburg O, Zachmann HG (1980) J Polym Sci Polym Phys 18:239

[211] Hosemann R (1950) Kolloid Z 117:13

[212] Kinning DJ, Thomas EL (1984) Macromolecules 17:1712

[213] Santos A, Yuste SB, López de Haro M (2002) J Chem Phys 117:5785

[214] Kamiyama T, Sasaki M, Suzuki K (2000) J Appl Cryst 33:447

[215] Kamiyama T, Suzuki K (1998) J Non cryst solids 232-234:476

[216] Boyer D, Tarjus G, Viot P (1995) J Chem Phys 103:1607

[217] Percus JK, Yevick GJ (1958) Phys Rev 110:1

[218] Bonnier B, Boyer D, Viot P (1994) J Phys A 27:3671

[219] Rényi A (1963) Sel Transl Math Stat Prob 4:203

[220] Rényi A (1958) Publ Math Inst Budapest 3:109

[221] Evans JW (1993) Rev Mod Phys 65:1281

[222] Kumar P (2002) J Inequal Pure and Appl Math 3:art. 41

[223] Balakrishnan N, Gupta SS (1998) In: Balakrishnan N.; Rao CR (ed.), Handbook of Statistics, vol. 17, chap. 2, pp. 25-59, Elsevier, Amsterdam

[224] Aggarwala R, Balakrishnan N (1996) Ann Inst Statist Math 48:757

[225] Varghese P, Braswell R, Wang B, Zhang C (1996) Comput Aided Des 28:723

[226] Burgos E, Bonadeo H (1987) J Phys A 20:1193

[227] Brämer R, Ruland W (1976) Makromol Chem 177:3601

[228] Weick D, Hosemann R (1980) Colloid Polym Sci 258:593

[229] Brämer R (1972) Colloid Polym Sci 250:1034

[230] Strobl GR (1973) J Appl Cryst 6:365

[231] Gelfer M, Burger C, Fadeev A, Sics I, Chu B, Hsiao BS, Heintz A, Kojo K, Hsu SL, Si M, Rafailovich M (2004) Langmuir 20:3746

[232] Vineyard GH (1982) Phys Rev B Condens Matter 26:4146

[233] Sinha SK, Sirota EB, Garoff S, Stanley HB (1988) Phys Rev B Condens Matter 38:2297

[234] Pynn R (1992) Phys Rev B Condens Matter 45:602

[235] Rauscher M, Salditt T, Spohn H (1995) Phys Rev B 52:16855

[236] Lazzari R (2002) J Appl Cryst 35:406

[237] Lee B, Park I, Yoon J, Park S, Kim J, Kim KW, Chang T, Ree M (2005) Macromolecules 38:4311

[238] Lee B, Park YH, Hwang YT, Oh W, Yoon J, Ree M (2005) Nat Mater 4:147

[239] Lee B, Yoon J, Oh W, Hwang Y, Heo K, Jin KS, Kim J, Kim KW, Ree M (2005) Macromolecules 38:3395

[240] Smarsly B, Gibaud A, Ruland W, Sturmayr D, Brinker CJ (2005) Langmuir $21: 3858$ 
[241] Ruland W, Smarsly B (2005) J Appl Cryst 38:78

[242] Benedetti A, Polizzi S, Riello P, Pinna F, Goerigk G (1997) J Catalysis $171: 345$

[243] Goerigk G, Haubold HG, Lyon O, Simon JP (2003) J Appl Cryst 36:425

[244] Friedel G (1913) C R Acad Sci 157:1533

[245] Lyon O, Guillon I, Servant B (2001) J Appl Cryst 34:484

[246] Ballauff M (2001) Curr Opin Colloid Interface Sci 6:132

[247] Fratzl P (2003) J Appl Cryst 36:397

[248] Kratky O (1933) Kolloid Z 64:213

[249] Kratky O (1933) Kolloid Z 68:347

[250] Hermans PH, Platzek P (1939) Kolloid Z 88:68

[251] Ward IM (ed.) (1997) Structure and Properties of Oriented Polymers. Chapman and Hall, London

[252] Pepper RE, Samuels RJ (1988) In: Mark HF, et al. (eds.), Encyclopedia of Polymer Science and Engineering, vol. 14, 2nd edn., pp. 261-298, Wiley, New York

[253] Ruland W (1977) Colloid Polym Sci 255:833

[254] Leadbetter AJ, Norris EK (1979) Mol Phys 38:669

[255] Burger C, Ruland W (2006) J Appl Cryst 39:889

[256] Ruland W, Tompa H (1968) Acta Cryst A24:93

[257] Thünemann A (1995) Structural transitions and microphase formation in homopolymers, copolymers and metallic carbonyles of acrylonitrile. Ph.D. thesis, Universität Marburg

[258] Thünemann AF, Ruland W (2000) Macromolecules 33:2626

[259] Keum JK, Burger C, Hsiao BS, Somani R, Yang L, Chu B, Kolb R, Chen H, Lue CT (2005) Progr Colloid Polym Sci 130:113

[260] Reiterer A, Lichtenegger H, Fratzl P, Stanzl-Tschegg SE (2001) J Mater Sci 36:4681

[261] Putthanarat S, Stribeck N, Fossey SA, Eby RK, Adams WW (2000) Polymer 41:7735

[262] Baltá Calleja FJ, Kilian HG (1988) Colloid Polym Sci 266:29

[263] Séguéla R, Prud'homme J (1988) Macromolecules 21:635

[264] Young P, Stein RS, Kyu T, Lin JS (1990) J Polym Sci Part B Polym Phys B28:1791

[265] Brandt M, Ruland W (1996) Acta Polym 47:498

[266] Murthy NS, Zero K, Grubb DT (1997) Polymer 38:1021

[267] Murthy NS, Grubb DT, Zero K (2000) ACS Symp Ser 739:24

[268] Murthy NS, T. GD (2006) J Polym Sci Part B Polym Phys 44:1277

[269] Murthy NS, Grubb DT, Zero K (2000) Macromolecules 33:1012

[270] Draper NR, Smith H (1980) Applied Regression Analysis, Second Edition. John Wiley \& Sons, New York

[271] Caceci MS, Cacheris WP (1984) Byte 1984:340 